\title{
Culture and Acculturation Influences on Palestinian Perceptions of Prenatal Genetic Counseling
}

\author{
Rawan Awwad • Patricia McCarthy Veach • \\ Dianne M. Bartels • Bonnie S. LeRoy
}

Published online: 13 May 2008

(C) National Society of Genetic Counselors, Inc. 2008

\section{Erratum to: J Genet Counsel DOI 10.1007/s10897-007-9131-2}

The text of the online publication and the printed publication of "Culture and Acculturation Influences on Palestinian Perceptions of Prenatal Genetic Counseling" (Volume 17, Number 1, February 2008, pp. 101-116, DOI: 10.1007/s10897-007-9131-2) contains an inaccurate reference to the location of the Palestinian Territories in the Middle East. The following corrections should be noted:

- On page 102, Section "Arab Americans," the second half of the paragraph starting on line fourteen should read:

The online version of the original article can be found at http://dx.doi. org/10.1007/s10897-007-9131-2

\section{R. Awwad}

Prenatal Diagnosis Center, California Pacific Medical Center,

San Francisco, CA, USA

\section{P. M. Veach $(\varangle)$}

Department of Educational Psychology, University of Minnesota, 206 Burton Hall, 178 Pillsbury Dr., SE,

Minneapolis, MN 55455, USA

e-mail: veach001@umn.edu

\section{M. Bartels}

Center for Bioethics, University of Minnesota,

Minneapolis, MN, USA

\section{B. S. LeRoy}

Department of Genetics, Cell Biology, and Development, Institute of Human Genetics, University of Minnesota,

Minneapolis, MN, USA
In comparison, there are roughly 5.1 million Palestinians living in the Palestinian Territories (the West Bank and Gaza Strip) and Israel who are also predominantly Muslim. Of those, about 3.8 million live in the Palestinian Territories (Palestinian Central Bureau of Statistics, 2001-2006), and they are referred to as "native Palestinians" in this study. About 1.3 million live in Israel (Israeli Central Bureau of Statistics, 2003) and are commonly known as "Arab Israelis."

- On page 103, Section "Purpose of the Present Study," the sentence beginning on line four should read, "Two groups were studied: 17 native Palestinians living in the Palestinian Territories; and 14 Palestinian Americans who were born and raised in the U.S."

- On page 104, Section "Materials and Methods, Participants, Sample Recruitment," 1) starting on the second line of the first paragraph should read, "native Palestinians living in the Palestinian Territories, either in the city of Ramallah or nearby village of Kharbata;"

- On page 104, Section "Materials and Methods, Participants, Sample Recruitment," the last two lines of the first paragraph should read, "(i.e., first to be born in the U.S. to parents who emigrated from the Palestinian Territories) were recruited."

- And on page 104, Section "Materials and Methods, Participants, Sample Recruitment," the sentence beginning on the sixth line of the second paragraph should read, "In the Palestinian Territories potential...."

The authors regret the errors. 